\title{
Timing residential photovoltaic investments in the presence of demand uncertainties
}

\author{
Mostafa Reisi Gahrooei* \\ Georgia Institute of Technology \\ 247 4th Street ESBE Lab, Atlanta GA 30332-0680 \\ Phone: (404) 385-7608 Fax: (404) 894-1641 \\ Email: mrg9@gatech.edu \\ Yuna Zhang \\ School of Architecture \\ Building technology Lab \\ Georgia Institute of Technology \\ 247 4th Street Room 265, Atlanta GA 30332-0680 \\ Phone: (404) 713-3022 \\ Email: yuna.zhang@gatech.edu
}

Baabak Ashuri, Ph.D., DBIA, CCP, DRMP

Associate Professor \& Brook Byers Institute for Sustainable Systems (BBISS) Fellow School of Building Construction/School of Civil \& Environmental Engineering Director, Construction Research Center (CRC)

Director, Economics of the Sustainable Built Environment (ESBE) Lab

Chair, Integrated Project Delivery Systems Masters Track

Georgia Institute of Technology

280 Ferst Drive Atlanta, GA 30332-0680

Phone: (404) 385-7608

E-mail: baabak@gatech.edu

Godfried Augenbroe

Professor

School of Architecture

Chair, the building technology doctoral program

Georgia Institute of Technology

247 4th Street Room 265, Atlanta GA 30332-0680

Phone: (404) 894-1686

Email: Godfried.Augenbroe@,coa.gatech.edu

*Corresponding Author 


\section{ABSTRACT}

As investment in residential photovoltaic systems is increasing at a rapid pace, it is important to investigate whether delaying or otherwise timing these investments can maximize long term investment gains. Conventional financial analysis methods for evaluating investment decisions in solar-electric system are all based on a one-time installation of the PV systems and cannot be applied to analyze the benefit of delayed and staged investment. Such benefits could be declining costs of PV systems thus tempting investors to hold off and wait for a better moment to invest. This paper proposes a decision making framework using the real option method to analyze the optimum time to invest in a residential PV system in different scenarios. A reference residential house is used to test the effect of different investment strategies. The results show the type of staged investment of installing residential PV system that maximizes the long-term payoff. This reveals when the option to delay investment is preferred. The supporting source code and data are available for download at https://github.com/reisiga2/SolarPanelInvestment.

Keywords: Solar Systems, Renewable Energy Investment, EnergyPlus Simulation, Real Option Valuation, Dynamic Programming

\section{INTRODUCTION}

The U.S. building sector accounts for seven percent of world's total energy consumption, which corresponds to $41 \%$ of the total energy usage and approximately half of the total greenhouse gas (GHG) emission in the United States [1-3]. This high-level of energy usage suggests that investing in building energy efficiency retrofits can effectively reduce a significant amount of energy consumption and ozone depletion caused by GHG emission at relatively low cost. In particular, investing in retrofitting residential buildings, which account for 54\% of the building sector's energy consumption [1], can make substantial contribution to the energy reduction. From the 
24 individual homeowner perspective this will reduce the household's energy usage, environmental 25 footprint, as well as its energy bills.

26 As one of the fast-growing emerging sustainable energy resources, solar energy has attracted

27 increasing attention worldwide. Recent decades have shown an increasing trend of implementing 28 photovoltaic (PV) systems in residential houses [4] as the PV system can partially or entirely fulfill 29 the household's electricity demand from a nonpolluting energy resource. However, effective 30 implementation of residential PV system requires the owner to make a large initial investment. The 31 return on this investment is affected by several uncertainties, such as future energy retail price and 32 technology costs, PV system performance, and house energy demand volatilities. These uncertainties 33 cause difficulties in the investment evaluation exacerbated by the limitation of traditional investment 34 techniques such as Net Present Value (NPV), Internal Rate of Return (ROR), and Discounted Cash 35 Flow (DCF) analysis [5-8]. These investment evaluation methods cannot provide an insightful 36 analysis of the financial benefit because they only consider investing at the current moment 37 neglecting that, in reality, the investment decision can be postponed to a future moment or 38 implemented in multiple stages. Because of the decreasing trend in the cost of solar panels and 39 potential increase in the retail price of electricity [9], postponing the investment may bring greater 40 benefits comparing to investing now. Therefore, providing better financial decision-making tools is 41 becoming increasingly important. Without a suitable financial decision analysis tool, the estimation 42 of investment risk may lack credibility to attract investor's money, even if the current investment 43 trend is leaning strongly in favor of PV system investments.

44 To address the limitations of traditional investment valuation, several authors have proposed the Real 45 Option Valuation (ROV) technique [5-8, 10-12] to apply to the building energy domain. Real options 
analysis provides opportunity to cope with investment timing under uncertainty. The term real options refers to the assessment of real (non-financial) investments with strategic management flexibility features like delayed improvement [13]. This field has gone through a massive transition from a topic of modest academic interest in the 1990s to the current considerable, active academic and industry attention $[14,15]$. Many promising renewable energy solutions, such as PV systems, are still in the early deployment stage and hence, their costs are typically high and their efficiency and effectiveness remain to be verified in practice over time. One cannot be certain about actual energy savings of these technologies due to uncertainty about their technical performance and deterioration rate. Investors require valuation methods enabling them to determine whether they should delay an improvement and when it becomes financially sound to adopt a technology [16].

Real options approach provides the opportunity for appropriate investment valuation by thinking about renewable energy systems as investment options. In the context of investment in building energy systems, a building owner with an opportunity to invest in energy is holding an "Option" analogous to a financial call option - he has the right but not the obligation to adopt an emerging technology in building energy intervention at some future time of his choice. Real Options Analysis is an alternative investment valuation analysis that supplements net present value (NPV) and return on investment (ROI) calculations. Appropriate real options analysis must be based on rigorously quantified underlying uncertainties of an investment project in a specific context. Also, these uncertainties must be properly integrated in the investment valuation of the project. Fundamental research is required to quantify the uncertainties in the context of investment decision-making about PV energy systems and properly integrate these uncertainties in the process of the building energy investment valuation. For example, [6], [7], and [8] used real option valuation framework to evaluate 
the potential investment in building energy efficiency systems, such as heating, ventilation and air conditioning (HVAC) system, lighting system, and roof insulation. [5], [10], and [11] proposed a real option framework for evaluating investment in solar ready buildings under the electricity price uncertainty and concluded that delayed investment can improve the total investment benefits. Similarly, [17] used a real option-based framework to calculate the governmental subsidy that incentivizes the implementation of solar panels in South Korea.

Although a few studies discussed the potential for staged investment in energy efficient retrofits [7, 8], to the best of our knowledge, no study has investigated the potential for staged investment in solar systems. In addition, studies on solar panel investment only evaluated the optimal time of investment using a real option approach, but did not provide recommendations on optimal sizing of panels. Moreover, they considered electricity price as the sole source of uncertainty and neglected the solar panels performance and building energy demand volatilities $[5,10]$. This paper demonstrates an investment analysis method which uses the dynamic programming to assist decision makers in finding the optimum investment strategies (in terms of investment time and the size of solar panels) when implementing a residential PV system in the presence of building demand uncertainties and unpredictable market fluctuations.

In the next section, we will discuss the modeling scheme for each of these uncertainties and introduce a framework which considers them in the evaluation of the value of delaying investment and the value of implementing the PV panels in multiple stages.

\section{STAGED ENERGY INVESTMENT DECISION ANALYSIS PLATFORM (SIDAP)}

In order to find the optimal staged investment strategy for residential PV system, we developed a staged energy investment decision analysis platform (SIDAP). Figure 1 illustrates the schematic 
structure of SIDAP. In this platform, we first create an energy model of the building with integrated PV system and simulate it in EnergyPlus [18]. EnergyPlus is one of many building energy dynamic simulation software programs; it is regarded as the US "gold standard" of energy modeling versatility and fidelity and therefore an appropriate choice for this research. A building energy model translates the physical interactions of building components into a differential-algebraic equation (DAE) set which are subsequently solved over time through numerical integration. The building energy model contains physical processes parameters about which our knowledge is imprecise. This lack of knowledge is incorporated in the building energy model as uncertainties, which fall in either of two categories: parameter uncertainties and model form uncertainties. The latter category incorporates the discrepancies of the model itself. In this study we conduct a building demand uncertainty analysis by propagating both uncertainties in energy model parameters as well as model form uncertainties in a Monte Carlo simulation approach [19]. It should be noted that a building energy demand uncertainty analysis is only as good as the underlying quantification of all sources of uncertainty. In this research we use the Uncertainty Quantification (UQ) repository that was developed previously in a large NSF funded effort with the specific purpose to support future building energy uncertainty analyses [20]. The UQ repository consists of uncertainty ranges of roughly 80 physical and 11 adapted EnergyPlus modules that quantify model form uncertainty as stochastic processes within the EnergyPlus simulation. Sources of uncertainty are distinguished at several scales of a typical building energy analysis:

- Urban scale: variability of microclimate parameters as result of urban heat island effect, local wind pressures and velocity as result of urban surroundings, as well as the translation of horizontal global and direct 
radiation to radiation on tilted surfaces. All of these have been quantified as model form uncertainties in new EnergyPlus modules.

- Material scale: variability of physical properties of materials, windows, absorptivity, reflectivity and others. These sources have been quantified as uncertainty ranges of current model parameters.

- Systems scale: variability in the performance of HVAC components, such as equipment tolerances and duct leakage. These sources have been quantified as uncertainty ranges of current model parameters.

- Scenario scale: variability in occupancy, and occupant interactions leading to uncertainty in schedule and temperature set points. These have been quantified as model form uncertainties.

Efforts are underway at the Argonne national Lab to incorporate the UQ in routine uncertainty analysis with the next generation of EnergyPlus.

The simulations are conducted through GURA-W [20] which delivers the simulation results as distributions of building energy demand and PV system production. GURA-W (Georgia Tech Uncertainty and Risk Analysis Workbench) was a byproduct of the same NSF project for the purpose of making uncertainty analysis available to the larger community. The workbench accepts any valid EnergyPlus input model, creates samples based on the ranges in the UQ repository, performs the simulation runs and combines the generated outputs into statistical representations, thus largely automating the uncertainty analysis. Although GURA-W is based on a standard Monte Carlo approach with Latin Hypercube sampling, it adds a lot of functionality that is adequate for a building energy uncertainty analysis. Among these functions we mention the freedom of the modeler to 
make a custom combination of parameter uncertainty and model form uncertainty, the ability to use

135 generated stochastic weather data if desired, and the use of so-called batch sampling. The latter is

136 relevant when the same product (e.g. a window) appears many times over in a building, in which

137 case the property of a window can be sampled independently, or sampled from a batch of similar

138 windows. Another important feature is flexible multi stage parameter sensitivity analysis, including

139 the option to perform parameter group sensitivity analysis. In the next step, we combine PV system

140 production results with energy price and PV installation cost models to estimate the profit of

141 installing a PV system in a given year. Based on the simulation results, we then use the dynamic

142 programming to choose the optimum time and optimum size of either a one-time installation or a

143 staged installation of the PV system. The next section will detail methods to identify and quantify the

144 building energy demand uncertainties, as well as technology and energy price changes leading to 145 probabilistic estimates of volatilities that are input to SIDAP. 


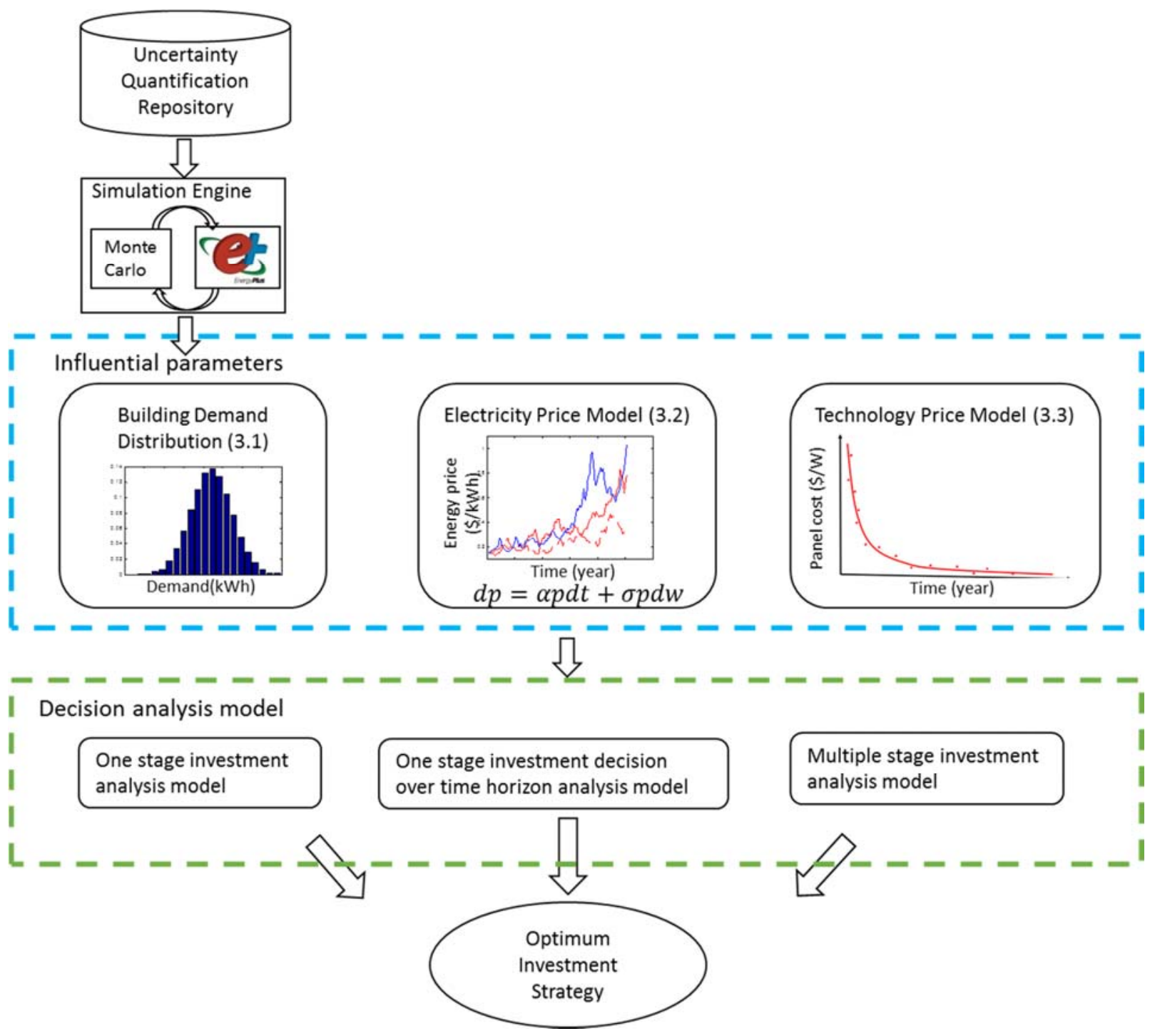

Figure 1 Schematic structure of SIDAP

\subsection{Building Performance Uncertainty}

Uncertainties in building performance simulation have different sources. The first source stems from imprecise knowledge of building and system physical parameters. For instance, the on-site system efficiency can deviate from the efficiency listed on the nameplate determined by the manufacturer under standard working conditions. Another source of uncertainty is model form uncertainty. Current state-of-the-art energy simulation software uses simplified mathematical models to represent complex physical phenomena that occur in reality. This simplification, which contributes 
171 have addressed uncertainties in building systems, e.g. [28] has summarized the uncertainty of PV

172 system efficiency in an off-grid solar house. [29] studied different sources of HVAC system

173 uncertainty, such as equipment manufacture tolerance, system degradation, and duct leakage; [30]

174 inspected the discrepancy between coupling and uncoupling simulation of a building and its systems

175 in the presence of system parameter uncertainties.

176

to the uncertainty in the building performance predictions, can lead to performance gaps between simulation results and real-world observations. Moreover, energy modelers make assumptions based on their domain knowledge which do only approximately represent the actual realized building. These assumptions contribute also to the performance gap between simulation and reality.

In order to understand the impact of these uncertainties on simulation results, several authors evaluated and analyzed each type of uncertainty within different scenarios. [19], [21], and [22] introduced a general procedure for uncertainty analysis in building thermal performance estimation. Uncertainties in the local weather arise from the incorporation of microclimate effects, such as the urban heat island effect [23] or from the fact that standard meteorological years reflect insufficiently the extreme weather periods. The latter can be somewhat averted by the utilization of Stochastic Meteorological Years [24]. One example of the characterization of model form uncertainty is found in [25] which deals with uncertainty analysis of the Perez model [26] which is widely used to calculate solar irradiance. Building level uncertainties are mainly caused by impreciseness in physical parameters, often caused by realization uncertainty as discussed in [27], which quantifies the impact of construction detailing and workmanship on building energy performance. Other studies in the presence of system parameter uncertainties.

All the studies above contribute to a growing body of knowledge that focuses on the impact of uncertainties in design and investment decision making. As mentioned above, this study uses the UQ 
178 (Uncertainty Quantification) repository that became available recently to capture all major building 179 energy model uncertainties that have been characterized by previous efforts. The energy model will 180 not be able to capture the full complexity of all possible real world translation from a given building

181 design but based on [31], we believe that we capture the major sources of uncertainty well enough. The uncertainties are propagated in the GURA-Workbench leading to probabilistic predictions of energy use and other outcomes of the EnergyPlus simulation tool.

\subsection{Electric Price Module (Market Uncertainties)}

Future price of electricity is one of major sources of uncertainty when evaluating the investment of residential PV systems. A decline in future retail price of electricity will reduce the PV system's total profit, and if it drops such that it cannot make up for the initial installation cost, the investment becomes a loss. Consequently, it is important to integrate a practical model for prediction of the electricity price with its trend in the future in the evaluation of the investment risk analysis to help investors.

A binomial lattice model was used in this study to model the evolving uncertainty of electricity price over time, in order to estimate future energy-saving benefits of PV systems. Binomial lattice is a discrete approximation of Geometric Brownian motion (GBM) stochastic process that has been widely used in the real options analysis literature. GBM has been a popular stochastic process choice to model evolving uncertainty in the real options analysis. A GBM process has a trend growth rate that is geometric, meaning growing at the same rate over time. A GBM process includes a random component as well. One of the most important reasons for the widespread use of GBM models in real options analysis is that calculations with GBM processes are relatively easy and tractable. There are just two parameters that need to be estimated, drift and volatility. Also, developing analytical 
solutions for real options problem is often possible due to the flexible mathematical structure of GBM process. GBM process and its approximate discrete form, binomial lattice, has been used in several studies $[5-8,10,16,32]$ to model uncertain electricity prices.

However, the use of GBM processes in real options analysis has not been without difficulties. Some underlying modeling assumptions may not hold in practice. For instance, the assumption of constant volatility rate over time may not be good in some problems. Also, GBM process is not a good modeling choice in capturing sudden substantial changes (jumps) of the underlying uncertain variable. Considering these issue, we empirically examine the appropriateness of GBM model to capture uncertainty in electricity prices. We conducted several statistical tests to examine whether GBM is an appropriate model for electricity prices used in our study. We have used actual electricity price data from 2001 to 2015 in the state of Georgia in the United States to test whether the GBM fits well to this dataset.

Monthly average prices of electricity in the state Georgia from 2001 to 2015 [33] were used in this study. We examined whether there is any statistically significant evidence against using the GBM process to model uncertainty in this electricity price dataset. A statistical approach proposed by [34] was utilized in this study to test the validity of GBM assumption for modeling evolving uncertainty of electricity prices.

First, an additive method [34] was used to adjust the initial electricity price data for seasonality. Figure 2 shows both original monthly average prices of electricity and its seasonally adjusted values from 2001 and 2015. The GBM is a stochastic process, in which the logarithm of the underlying quantity follows a Brownian motion (similar to a random walk process). Two conditions of normality and independence need to be examined to assess the appropriateness of 
222 GBM modeling assumption for the seasonally-adjusted electricity price dataset. Suppose p1, $223 \mathrm{p} 2, \ldots, \mathrm{pn}$ are seasonally-adjusted prices of electricity in time step $1,2, \ldots, \mathrm{n}$, respectively. This 224 path of data follows a GBM process if [34]

225

226

227

228

229

230

231

232

233

234

235

236

237 238

27

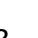

29

1) $\mathrm{Wi}_{\mathrm{i}}=\log (\mathrm{pi}+1 / \mathrm{pi})$ follows a normal distribution; and

2) For every i, $w_{i}$ and $w_{i+1}$ are independent.

230

Figure 2 Monthly average electricity price in Georgia, U.S.A., from 2001 to 2015, and its seasonally
adjusted values

Figure 2 Monthly average electricity price in Georgia, U.S.A., from 2001 to 2015, and its seasonally
adjusted values

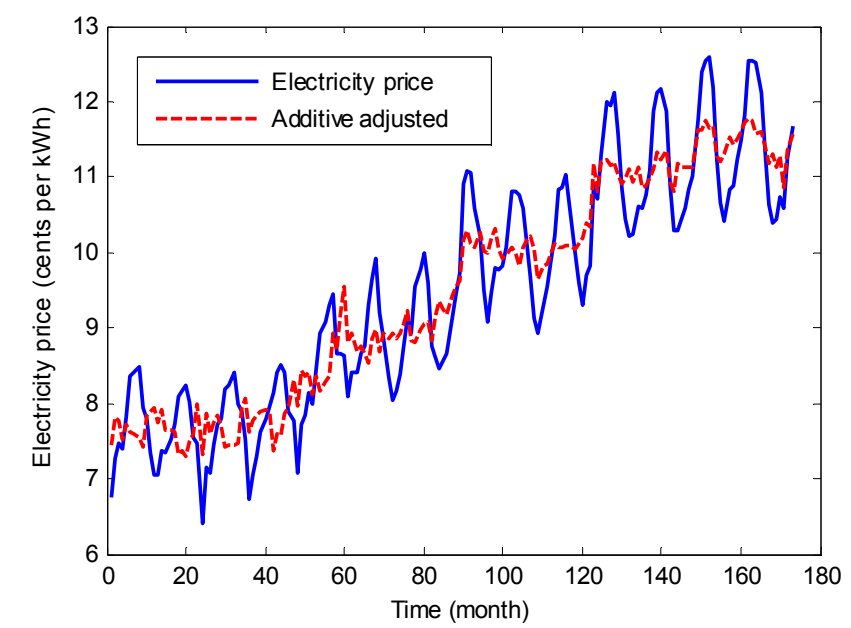
1

One-sample Kolmogorov-Smirnov and Shapiro-Wilk tests were used to examine whether the assumption of normal distribution holds true for the log-ratio of seasonally-adjusted electricity prices. Table 1 shows the results for both tests. Based on the results, it is concluded that both normality tests failed to reject the null hypothesis at 5\% level of significance. Hence, there is no statistically significant evidence found to reject the normal distribution assumption for the electricity price dataset. 
Table 1 Results of two normality tests conducted on the log-ratio of seasonally-adjusted electricity prices

\begin{tabular}{|c|c|c|c|c|}
\hline Statistical Test & $\begin{array}{c}\text { Level of } \\
\text { Significan } \\
\text { ce }\end{array}$ & $\begin{array}{c}\text { Test } \\
\text { statistic } \\
\mathrm{s}\end{array}$ & $\begin{array}{c}\text { Critica } \\
1 \\
\text { Value }\end{array}$ & $\begin{array}{c}\text { P-valu } \\
\mathrm{e}\end{array}$ \\
\hline Shapiro-Wilk & 0.05 & 0.9846 & $\sim 0.99$ & 0.058 \\
\hline Kolmogorov-Smirnov & 0.05 & 0.0969 & 0.1040 & 0.0812 \\
\hline
\end{tabular}

The run test for independency [35] was used to examine the second condition. Results of the run test is summarized in Table 2. The results indicate that the null hypothesis cannot be rejected at 5\% level of significance and therefore, no statistically significant evidence was found against the independency assumption of GBM modeling choice in the electricity price dataset studied here.

Table 2 Run test for independency of the seasonally adjusted electricity price

\begin{tabular}{|l|l|l|l|c|}
\hline $\begin{array}{l}\text { Statistical } \\
\text { Test }\end{array}$ & $\begin{array}{l}\text { Level of } \\
\text { significance }\end{array}$ & $\begin{array}{l}\text { Test } \\
\text { statistic }\end{array}$ & $\begin{array}{l}\text { Critical } \\
\text { value }\end{array}$ & P-value \\
\hline $\begin{array}{l}\text { Run test for } \\
\text { independency }\end{array}$ & 0.05 & 0.3 & 1.96 & 0.6179 \\
\hline
\end{tabular}

In summary, the results of both tests show that there is no statistically significant evidence to reject

251 the GBM modeling assumption in this study and hence, GBM process can be considered as a good

252 modeling choice for modeling evolving uncertainty in electricity prices.

253 Let $p(t)$ represents the retail price of electricity, which follows a GBM, then

$$
d p=\alpha p d t+\sigma p d B(t)
$$
where $\alpha$ and $\sigma$ are the expected annual growth rate and the volatility of the retail price of electricity,

255 respectively, and $B(t)$ represents a Brownian motion. The expected price of electricity modeled by 256 the GBM can be calculated as $p=p_{0} \exp (\alpha t)$, where $p_{0}$ is the price of electricity at the initial time. 
257 We will later use this expectation to calculate the value of the project. To estimate the values of $\alpha$ and $\sigma$, one could fit the model to historical data of the electricity price [10].

\subsection{Solar Panel Cost Module (Technology Changes)}

The implementation cost of building energy efficiency technologies might decrease over time due to economy of scale, raw materials price declines, R\&D processes, and product innovations [10]. In general, if it is expected that the solar system cost reduces rapidly in future, delaying the investment in solar system can be beneficial. On the contrary, if the predications indicate a stable PV market, investing in solar panel as early as possible can be a better option. As a result, when evaluating the investment in residential PV systems, it is critical to consider the changes in technology costs and its effects on solar investments in an integrated valuation framework that considers decline in PV costs combined with several other factors, such as building energy demand and electricity price.

Several studies $[36,37]$ showed that cost of PV modules is subject to significant decline over time. Cost of PV modules follows the economy of scale. For instance, [36] showed that each time the cumulative production doubled, the implementation cost of solar panels went down by $19.6 \%$ for the last 34 years. [10] modeled the exponential decline in cost of PV modules using an experience curve formulation. Several estimates have been provided in the literature for progress ratio in experience curve formulation, for instance, [38, 39] provided estimates between 0.7 and 0.85 for decreasing costs of PV panels. We have utilized historical costs of PV modules provided in a dataset maintained by the Fraunhofer Institute for Solar Energy Systems [40] to study the decreasing trend in cost of PV modules. Figure 3 shows average annual costs of PV modules from 1980 to 2012. It can be seen that the economy of scale (i.e., experience curve) exists in the PV market and the decreasing trend of cost 
279 of PV modules follows a smooth exponential decline formulation. Therefore, in this study, the

280 decreasing cost of PV modules over time is modeled by the following formulation:

$$
C_{t}=C_{o} e^{-\gamma t}
$$

281 In (2), $C_{0}$ is the cost of solar panel at the initial time (time 0 ), and the value of $\gamma$ determines how 282 fast the installation cost of solar panels is expected to decline over time. The estimates of these 283 model parameters are shown in Figure 3 for the PV cost dataset provided in this study.

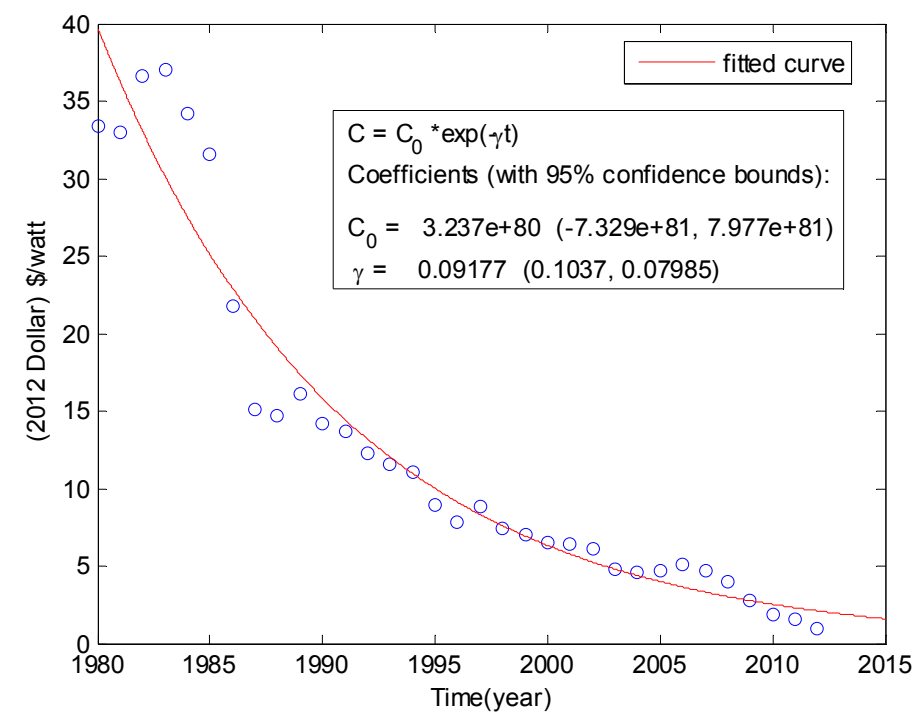

Figure 3 Cost of solar panel data [40] and an exponential fitted curve

As the value of $\gamma$ in (2) grows larger, the cost decline faster and therefore waiting to invest in solar systems becomes a competing option. However, if $\gamma$ takes a very small value indicating that the solar system market is stable, and that the price of solar panels might not change in the future, investing in solar panel as early as possible can be a better option. In section 4.2, the effects of this parameter on the investment timing will be analyzed.

\subsection{Mathematical Formulation and Dynamic Programming}

In order to develop a mathematical framework for the investment evaluation, we assume that 
the price of energy $p(t)$ follows a GBM with growth rate of $\alpha$ and volatility $\sigma$, and that the cost of installing the solar panels declines exponentially with some rate $\gamma>0$. We assume a fixed cost, $m$, for maintaining the installed PV system. We state that the solar panel generates $z(k W h)$, and the household consumes $D(k W h)$ on average during a year, and $T$ is the investment horizon in years. Throughout this study, we assumed that the investment horizon is fixed at $T$ years, i.e., opportunity to invest in solar energy will expire after $\mathrm{T}$ years from now and investment decision in solar energy must be made sometime between now and the end of investment horizon. If the building owner decides not to invest during this period the investment expires in year $\mathrm{T}$ and the terminal value will become 0 in year $\mathrm{T}$. The value of investment horizon $\mathrm{T}$ is specified by the building owner (or investor) for the investment under studied (i.e., $\mathrm{T}$ is an input parameter to our investment valuation model. We assume that the surplus electricity production $(z-D)$ can be sold back to the grid at $\epsilon p(t)$, where $\epsilon$ is the sellback ratio, and $p(t)$ is the price of electricity sold by the utility company ${ }^{1}$. Building owners that have PV systems installed at their properties produce electricity for their own demand and have the option to sell the excess generated electricity back to the grid. The rate at which the excess electricity is purchased is determined by the utility company, depending on the contract time and duration. The sellback ratio is the ratio of the rate at which the excess electricity is sold back to the grid to the rate at which the electricity is bought from the grid. For example, Sacramento Municipal Utility District (SMUD) purchases the electricity back in summer (on peak hours) in a 10-year contract at the rate of about 6.6 cents/kwh [41]. SMUD sells the electricity at rate of 10

1 In the U.S., the Public Utility Regulatory Policy Act (PURPA) regulates electric utilities on the traditional power grid to buy the excess electricity that renewable energy systems generate. 
312 cents/kwh during the summer [42], and therefore, the sellback ratio is 0.66 . Given these assumptions, 313 the expected energy saving value, $V(t, p)$, of installing a solar system at time $t$ is

$$
V(t, p)=\int_{t}^{T}\left(Z p(t) e^{\alpha \tau}-m\right) e^{-r \tau} d \tau
$$

314 where $0 \leq \mathrm{t} \leq \mathrm{T}, r$ is the annual discount rate, and $Z=z$ when $(z<D)$, and $Z=(1-\epsilon) D+\epsilon Z$ 315 when $(z>D)$. Here, D represents mean value of annual building energy demand and $\mathrm{z}$ is the mean 316 value of annual solar energy generation by the installed PV system. In this study, we assume that 317 both of these parameters do not change from a year to another and therefore, there is no need for

using double integration in (3). Since the electricity price follows a GBM form the expected value of electricity price at time $\tau$ can be calculated as the following exponential function: $E(p(\tau))=p_{0} e^{\alpha \tau}$ where $p_{0}$ is the initial price of electricity and $\alpha$ is the drift parameter of the GBM process. This expected value is used in calculating the integral in (3). In this formulation, $Z p(t) \exp (\alpha \tau)$ gives the total value of the electricity produced by the solar system at the year $\tau$, and $\exp (-r \tau)$ is a continuous discount factor, and by integrating over all the investment horizon (from $\mathrm{t}$ to $\mathrm{T}$ ) the total investment project is calculated. Now, by taking the expected value over the electricity price, and considering that $E(p)=p_{0} \exp (\alpha t)$, we obtain

$$
\begin{array}{r}
V(t, p)=\frac{p Z}{\alpha-r}\left(e^{(\alpha-r) T}-e^{(\alpha-r) t}\right) \\
-\frac{m}{r}\left(e^{-r T}-e^{-r t}\right),
\end{array}
$$

where $E$ represents the expected value function, and $p$ is the price of electricity at the installation time, $t$. With this formulation of the energy saving value, one can use dynamic programming to identify the expected optimal time, size, and value of investment in a PV system of any size.

\subsubsection{Investment with predetermined size of panels and with no option to wait}

With no option to wait, and a fixed size of solar panel, the problem is reduced to finding the 
expected NPV as

$$
N P V=V\left(0, p_{0}\right)-C_{0}
$$

332 In our case studies, we will evaluate how NPV behaves for different sizes of solar panels and 333 different values of the electricity price growth parameter $\alpha$.

334 3.4.2. Single phase investment with a predetermined size of panel and option to wait

335 The single phase investment in a fixed size solar panel can be modeled as an optimal stopping 336 problem [13] in which, at any given time $t$, one can invest in installing the PV panels with the cost of $337 C(t)$, or can wait until a future moment, when more information is available.

Let $F(t, p)$ denote the optimal expected value of the project at time $t$ when the retail price of electricity is $p(t)$. This value is equal to the maximum of the value obtained from investing at time $t$,

340 or the value that can be obtained in the future, and thus can be written as

$$
F(t, p)=\max \{N P V(t, p), h(t, p)\}
$$

341 Here, $N P V(t, p)=V(t, p)-C(t)$ and $h(t, p)=(1 /(1+r d t)) E(F(t+d t, p+d p))$.

342 In this paper, we will find the optimal investment value $(F(0, p))$ numerically by discretizing the project time horizon into equal time steps, and by assuming that $T$ is a large value. Let $t=0,1, \ldots, T$

344 represent each time step at which an investment decision (invest or wait) should be made. Then the 345 discrete form of $(6)$ is

$$
\begin{aligned}
& F\left(\mathrm{t}, \mathrm{p}_{\mathrm{t}}\right)=\max \left\{\mathrm{V}\left(\mathrm{t}, \mathrm{p}_{\mathrm{t}}\right)-\mathrm{C}(\mathrm{t})\right), \\
&\left.\frac{1}{(1+\mathrm{r})} \mathrm{E}\left(\mathrm{F}\left(\mathrm{t}+1, \mathrm{p}_{\mathrm{t}+1}\right)\right)\right\}
\end{aligned}
$$

To find the optimal expected value of the project discounted to time zero, $F\left(0, p_{0}\right)$, we start at the terminal time, $T$, and recursively calculate $F\left(t, p_{t}\right)$. This recursive calculation is doable because 
$F(t, p) \rightarrow 0$ as $\mathrm{t} \rightarrow \mathrm{T}$.

\subsubsection{Multi-phase investment}

The multi-phase investment can be modeled as a dynamic programming problem, in which the optimal size of solar panels at each given time should be determined. Let's assume that $u(t), 0 \leq$ $u \leq u_{\max }$ represents the size of panel at time $t$, and $F(t, u, p)$ denotes the optimal net present value at time $t$ assuming that all decisions will optimally be made in the future. The investment decision in this problem is to increment (or not) the size of the solar panel at each decision node to increase the total investment return. Hence one can calculate $F(t, u, p)$ as

$$
\begin{gathered}
F(t, u, p)= \\
\max \left\{\frac{1}{1+r d t} F(t+d t, u(t+d t), p+d p)\right\}
\end{gathered}
$$

We will find the optimal investment value, $F\left(0, u^{*}, p\right)$, numerically by discretizing the project time horizon into equal time steps. Assume that at each given time step $t, t=0,1, \ldots, T$, the panel size can take a value $u\left(m^{2}\right), u=u_{0}, u_{1}, \ldots, u_{m}$. At each time $t$, the investor decides to increment the solar panel size from $u_{i}$ to $u_{j} \geq u_{i}(i, j=0,1, \ldots, m)$ with the cost of $C_{u_{i}, u_{j}}^{t}=\left(u_{j}-u_{i}\right) C(t)$, to increase the potential for renewable energy production. Here, $C(t)$ represents the solar panel installation cost per square meter at time $t$. Note that we assume that the installation panel cost changes linearly by the size of the panel. The value of energy production profit during the year $t$, depends on the price of energy at that time, and can be determined by:

$$
V(t, p)=(Z p(t)-m) e^{-r t}
$$

365 Therefore, the problem can be rephrased as identifying the optimal decision trajectory (selecting the 
installation size of solar panels at different moments) given the cost of transitioning from one size to a larger size, when each transition results in potential energy saving values. Figure 4 illustrates the case, when the investor, at each time step, should decide how much to increase the size of the panel (over the four possible choices) to maximize his return. For example, it is optimal for the investor not to change the size of panel in the first year, but increase it at second time step. To solve this problem, we again start at the terminal time and recursively calculate the optimal sub-path to find the optimal trajectory. This is possible because the investment value at the terminal time is known and is equal to zero. Note that this calculation is a backward one, and considers the future decisions when identifying the current optimal decisions.

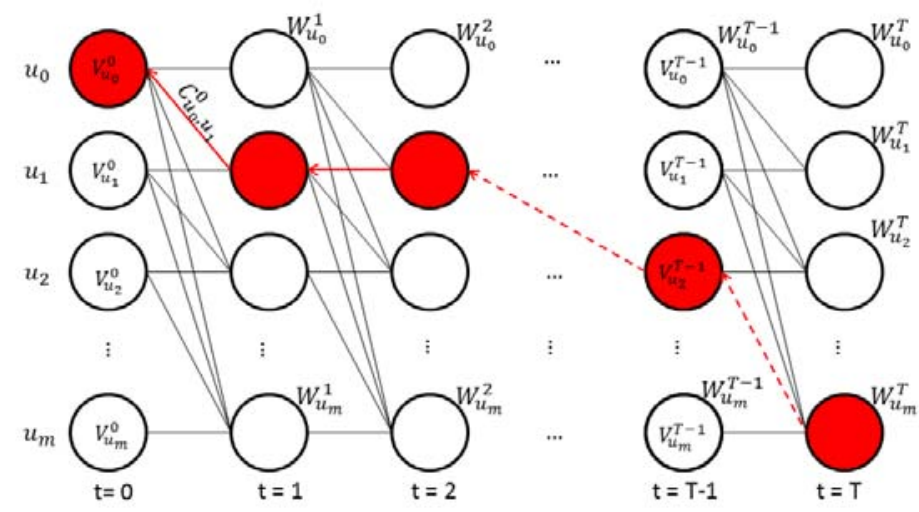

Figure 4 Illustration of the dynamic programing method used to find the optimal path of investment on solar panels. Each circle represents a panel size at a given time.

The following steps describe our approach of finding the optimal investment path for sizing the solar panels given the network illustrated in Figure 4:

1) Calculate the expected value of energy generated by the solar panel for year $t, V_{u_{i}}^{t}$, given the size of the panel, ui at time t. This can be calculated by $(Z p(t)-m) e^{-r t}$.

2) Calculate the cost of transitioning from one node to another node $\left(\mathrm{C}_{\mathrm{u}_{\mathrm{i}}, \mathrm{u}_{\mathrm{j}}}^{\mathrm{t}}\right)$. This is equivalent to the cost of purchasing and installing new solar panels. Note that this cost 
depends on time, and size of panels, and should discounted back to time zero. Finally, we assume linear relation between the cost of panels and their size.

3) Assume the optimal path and total value for reaching a decision node which represents a panel size of $u i$ at time $\mathrm{T}-1$ is known and is denoted by $\mathrm{P}_{\mathrm{u}_{\mathrm{i}}}^{\mathrm{T}-1}$ and $\mathrm{W}_{\mathrm{u}_{\mathrm{i}}}^{\mathrm{T}-1}$. Note that $\mathrm{W}_{\mathrm{u}_{\mathrm{i}}}^{\mathrm{T}-1}$ is the sum of all the benefits that add up until time T-1 to reach a node with panel size $\mathrm{u}_{\mathrm{i}}$ in the network. Now, given $\mathrm{W}_{\mathrm{u}_{\mathrm{i}}}^{\mathrm{T}-1}$ and $\mathrm{V}_{\mathrm{u}_{\mathrm{i}}}^{\mathrm{t}}$ for every node, calculate $\mathrm{W}_{\mathrm{u}_{\mathrm{j}}}^{\mathrm{T}}$ for every possible panel size $u_{j}$ at time $T$. This is simply $\max _{u_{i}}\left\{W_{u_{i}}^{T-1}+V_{u_{j}}^{T}-C_{u_{i}, u_{j}}^{T-1}\right\}$ over all possible solar panel sizes $u_{i}$, at time $\mathrm{T}-1$.

4) Since $W_{u_{i}}^{T-1}$ is not known, follow step 3 to calculate this value. Similarly, continue calculating $\mathrm{W}_{\mathrm{u}_{\mathrm{i}}}^{\mathrm{t}}$ for every time step $\mathrm{t}$ and every panel size ui.

5) Now with all the values of $W_{u_{i}}^{t}$ calculated at every $t$ and ui, start at time $T$ and find $\max _{\mathrm{u}_{\mathrm{i}}} \mathrm{W}_{\mathrm{u}_{\mathrm{i}}}^{\mathrm{T}}$, and the link that achieves this value.

6) Repeat the previous step for every t to find all the links that corresponds to the optimal path

\section{CASE STUDY}

As an illustration, a single-family detached house (Figure 5) located in four different climates (Phoenix, Atlantic City, Atlanta and Chicago) in the United States is tested in a case study. The total floor area of the two-story house is $300 \mathrm{~m}^{2}$. The HVAC system consists of an air supply system driven by a constant volume fan that blows in warm air heated by an electric furnace and cool air chilled by an electric cooling coil. The room set-point temperature is $24^{\circ} \mathrm{C}$ for cooling and $22^{\circ} \mathrm{C}$ for 
heating. The electronic equipment modeled in the residence include a refrigerator, a dish washer, a set of laundry machine, and plug loads from appliances and lighting, etc.

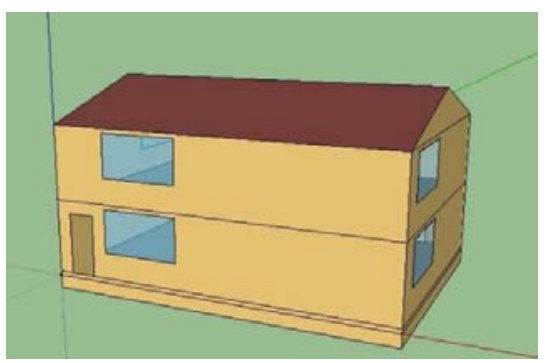

Figure 5 EnergyPlus model of the case study building

We choose the SunPower SPR-245 NE Mono-c-Si PV modules and target the right investment strategy installing this PV system on the case study house. The efficiency of this module is $19.7 \%$. The initial cost of the PV panel is $\$ 100$ per square meter, and the balance of system (BOS) cost is \$420 per square meter. The BOS cost includes the inverter cost and hardware cost which includes equipment and wiring to mount and connect the modules, installation labor fee, and grid connection fee, etc. The total initial installation cost is the sum of the cost of the PV panel and BOS, and will remain fixed over all researched scenarios. Table 3 lists the cost information of the PV system. The expected system life is 30 years. The maximum available area of the roof for the PV system is $60 \mathrm{~m}^{2}$. The goal of the case study is to explore the possibility of different investment strategies, represented by the described research scenarios, and to find the optimal investment which can help the decision maker achieve maximum profit in PV system investment. To compare the benefit of different investment strategies, all the income earned by installing the PV system during the life span will be discounted to the value in the first year at a constant interest rate (5\%/year compounded annually). 
Table 3 Cost information for the PV system

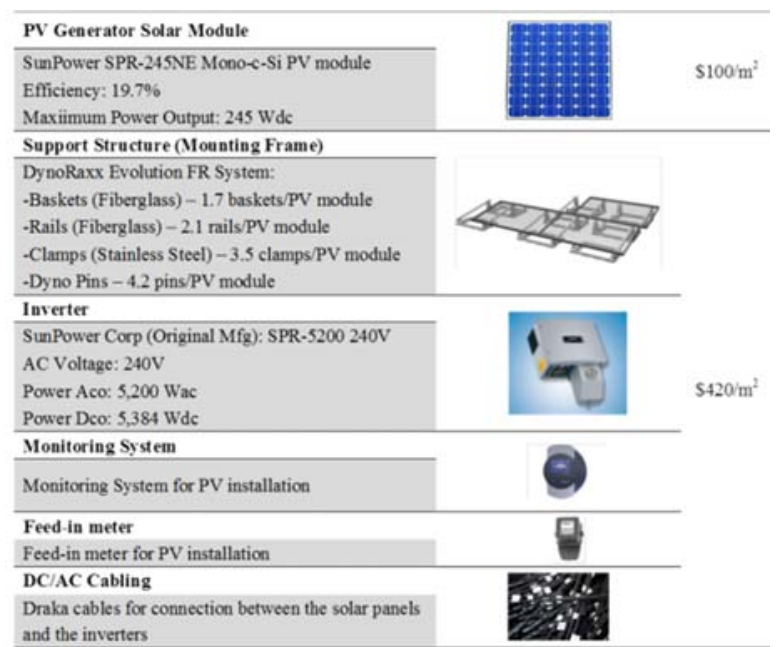

\subsection{Investment Scenario 1: Investment without considering time}

This section investigates the optimal size of a residential PV system without considering

429 investment time. [43] investigated the optimal size of a residential PV system and concluded that

430 when considering the impact of sellback price to the right sizing of a residential PV system, low

431 sellback rate may punish the household for installing an oversized system. Due to the fact that the

432 surge in distributed generation may threaten the stability of the power grid, we assume the sellback

433 rate is always less than the retail electricity price. Similar to the study in that paper, this paper fixes

434 the sellback rate to half of the retail electricity price and uses that as a exemplary baseline in different

435 investment scenarios. In scenario-1, we will find the right size of the PV system which can bring the

436 homeowner the maximum payback (expected NPV) of their investment at the fixed sellback rate.

437 Here, it is assumed that the investor either invests now or never. The outcome will be used as

438 baseline investment option to be compared with the outcomes of the other scenarios that inspect the

439 impact of timing on the NPV of the PV system.

440 In order to calculate the E(NPV), we first run EnergyPlus to obtain several random samples for 
441 building energy demand (D) and the amount of electricity produced by the PV system. Then, we 442 multiply each on-site use electricity and surplus electricity with the randomly generated retail price 443 and sellback price, respectively. Random streams of retail electricity prices and sellback prices are 444 generated by simulating the GBM model of the price with initial value of 9.69 cents/kwh. For each 445 random sample, the NPV of installing the PV panel for the selected size will be calculated. The 446 calculation process will be repeated multiple times for the generated random samples. The average of 447 these calculated NPVs represents the E(NPV) of the immediate investment of the selected PV size. 448 We repeat this process for different sizes of the PV system to find the right size that brings the 449 maximum payback. Figure 6 indicates that when $\alpha=0.02$, the maximum E(NPV) (\$5734) is 450 obtained with solar panel size of $24 \mathrm{~m}^{2}$.

451 Next, the relationship between the value of $\alpha$ and the optimum size of the PV system is investigated. 452 The goal is to understand how sensitive the sizing of a residential PV system is to the variation of 453 electricity price growth rate, $\alpha$. Figure 7 illustrates the heat map of $E(N P V)$ for different values of $\alpha$ 454 and solar panel sizes. It is noticeable, when $\alpha<0.03$, i.e., the growth rate of electricity price is 455 moderate, the homeowner get punished by installing an oversized system because the sellback ratio 456 of 0.5 decides that the surplus electricity that one needs to sell back to the grid is worth less 457 compared to the amount that is used directly onsite. 


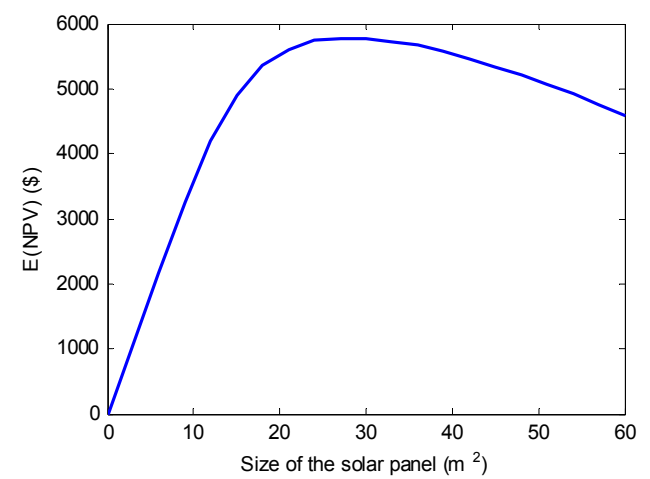

Figure $6 E(N P V)$ versus the size of the solar panel $(\alpha=0.02)$

However, when the growth rate $(\alpha)$ of electricity price is high $(\alpha>0.03)$, the benefit of installing a large-size system and producing more electricity for on-site use offsets the punishment of installing an oversized system and the NPV increases as the system size increases. Hence, for larger values of $\alpha$, the maximum size of the PV system $\left(60 \mathrm{~m}^{2}\right)$ is always beneficial because the increasing price of electricity increases the profit of the PV system.

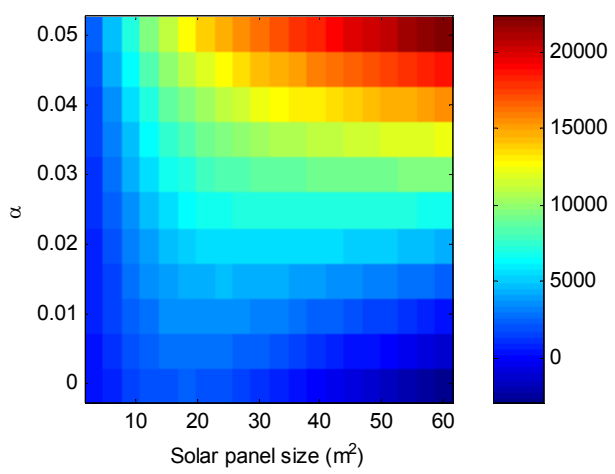

Figure $7 E(N P V)$ with respect to solar panel size and electricity growth rate, $\alpha$

We are also interested in the sensitivity of building demand volatility to the distribution of NPV. Assume therefore an increase in the electric plug load variability. This creates a large variation in the building energy demand. Figure 8 shows, not surprisingly, that as the volatility of building demand increases, the range of the NPV distribution also increases. The results show that when the sellback ratio equals to 0.5 , and the building has small demand variation $(s t d=1)$, the mean of NPV is 
$473 \$ 7600$ with lower bound at $\$ 6800$ and upper bound at $\$ 8400$. When the building has large demand

474 variation $(s t d=2)$, the mean of NPV turns out to be $\$ 7700$ with lower bound at $\$ 6000$ and upper

475 bound at $\$ 9000$. The (small) shift in the mean of NPV is because the larger demand variation has

476 more probability of using more on-site generated power which has a higher energy-saving benefit

477 compared to the power that is sold back to the grid.

478 This study also finds that the sellback rate plays an important role on the sensitivity of $E(N P V)$ to the

479 variation of building energy demand. The benefit of the PV system comes from two parts: the 480 electricity generated that used directly on site and the surplus generation that is sold back to the grid 481 at a discounted sellback rate. When this sellback ratio is equal to one, which means there is no 482 difference in the financial benefit between directly used onsite generated power and sold back 483 surplus generated power, the profit of the PV system is only related to the performance of the PV 484 system, the local weather, and volatility in electricity price. It is interesting to recognize that, in this 485 case, the variation of building energy demand has no impact on the distribution of the estimated PV 486 profit. Figure 9 shows that when the sellback ratio is equal to 1, the distribution of the NPV at small 487 building demand variation is virtually the same as the distribution for the large building demand 488 variation. 


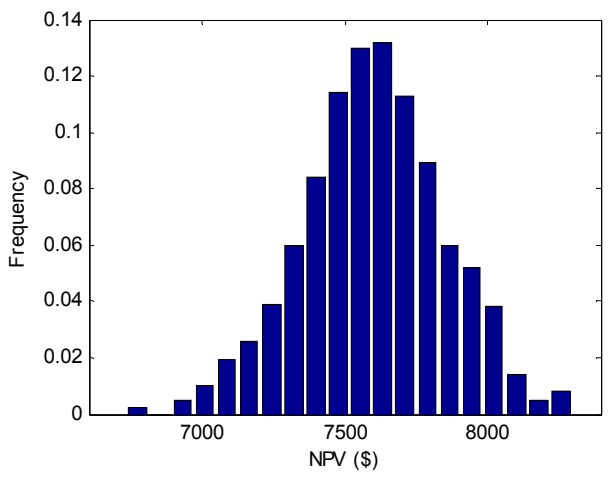

(a)

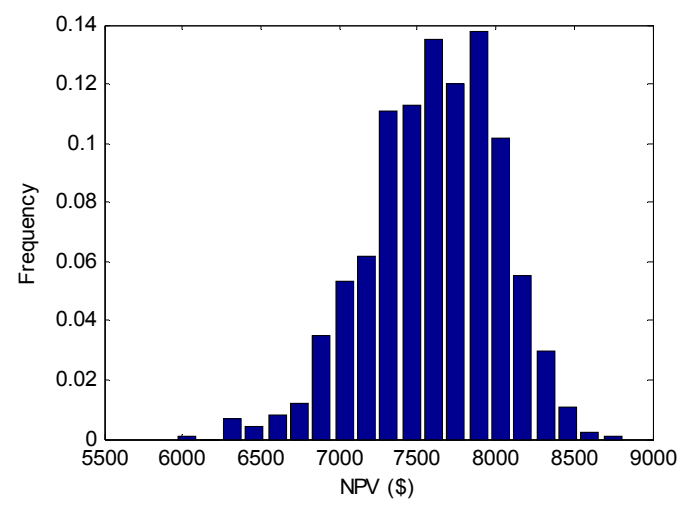

(b)

Figure 8 Distribution of NPV due to demand volatilities when sellback ratio $=0.5$ (a) small demand volatilities $(\mathbf{s t d}=1)(\mathrm{b})$ large demand volatilities $(\mathbf{s t d}=2)$

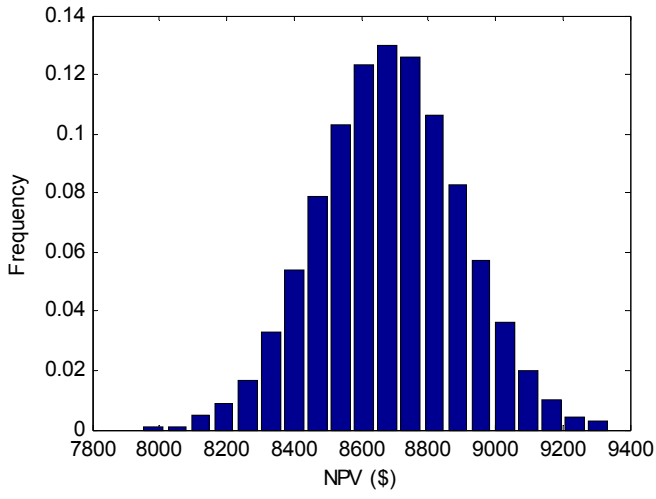

(a)

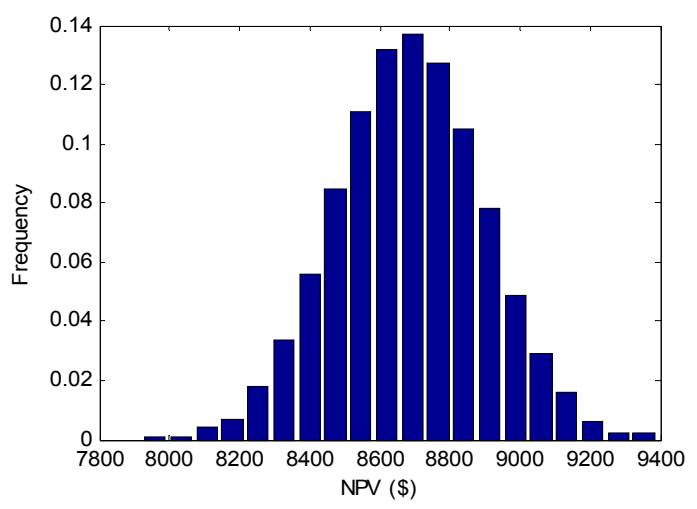

(b)

Figure 9 Distribution of NPV due to demand and energy price volatilities when sellback ratio=1 (a) small demand volatilities $($ std $=1)(b)$ large demand volatilities $($ std $=2)$ 


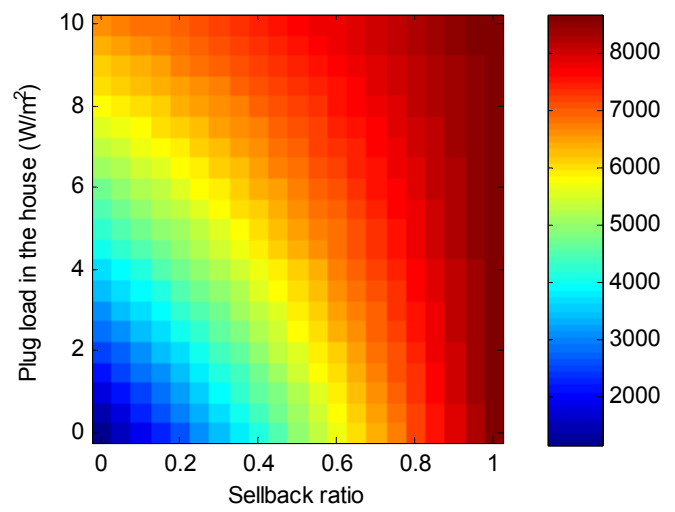

Figure 10: Expected NPV for different plug loads and sellback ratios

Figure 10 illustrates the heat map of $E(N P V)$ for different values of sellback ratio, $\epsilon$, and plug load in the house. The result shows that when sellback ratio is less than one, as the plug load increases, the $E(N P V)$ of the PV system increases because more electricity is used on site as a result of the increased energy demand; when the sellback ratio is equal to one, the change in building energy demand has no impact on the $E(N P V)$ of the system.

\subsection{Investment Scenario 2: The role of timing in PV investment}

This scenario investigates the impact of the investment time on the residential PV system investment payback, considering price and building energy demand uncertainty. Here, we fix the size of the solar panels to $24 \mathrm{~m}^{2}$, and the parameters of the electricity price model to $\alpha=0.02, \sigma=0.1$, which we use to generate 10,000 electricity price trajectories. Moreover, we have 1000 runs of EnergyPlus to capture the effect of energy demand and building uncertainties on the NPV calculation. In addition, we consider the decline of installation cost of residential PV system over time by using the experience curve model, $C_{t}=C_{o} e^{-\gamma t}$. With all these inputs, we determine the expected optimal time, and expected investment value along with their distributions for different values of $\gamma$ using the scheme introduced in Figure 1. 
508

509

510

511

512

513

514

515

516

517

518

519

520

521

522

523

524

525

526

Figure 11 shows the distribution of the optimal $E(N P V)$ and investment time under different rates of decline in solar panel cost, $\gamma$. When $\gamma=0.02$, Figure 11(a), the decline in the PV installation cost does not shift the investment time significantly. In fact, it is optimal to invest in the solar panels immediately 80 percent of the times. However, as the value of $\gamma$ increases, both the NPV value as well as the optimal investment time shifts to the right which indicates the value of postponing the investment. For example, when $\gamma=0.04$ (Figure 11(b)), it is more likely to gain more from the investment by postponing the investment 2 to 5 years, and when $\gamma=0.06$, (Figure 11(c)), 5 to 15 years delay in investment can bring more benefit. Thus, if it is anticipated that the PV technology cost drops at a sharp rate the investors can compensate for the profit they could earn from the PV production, by saving a great amount of money merely from the decreased installation cost.

We are also interested in understanding how timing of the investment will change as a result of the change in the size of the PV system. In other words, if the homeowner decides to increase or decrease the size of the system from that of the optimal calculated size (i.e., $24 \mathrm{~m}^{2}$ ), which direction will the optimal investment time shift to and how much financial benefit will this shift bring to the investor? To answer to this research question, we choose twenty different sizes of the residential PV system with increasing intervals equals to $3\left(\mathrm{~m}^{2}\right)$ and study the impact of installation timing on the calculated NPV and compare the calculated optimal expected NPVs with the expected NPV of the baseline scenario. Figure 12(a) illustrates that when the size of the solar system increases and the installation cost drops at the rate higher than $2 \%$ (i.e., $\gamma>0.02$ ), the optimal expected NPV 

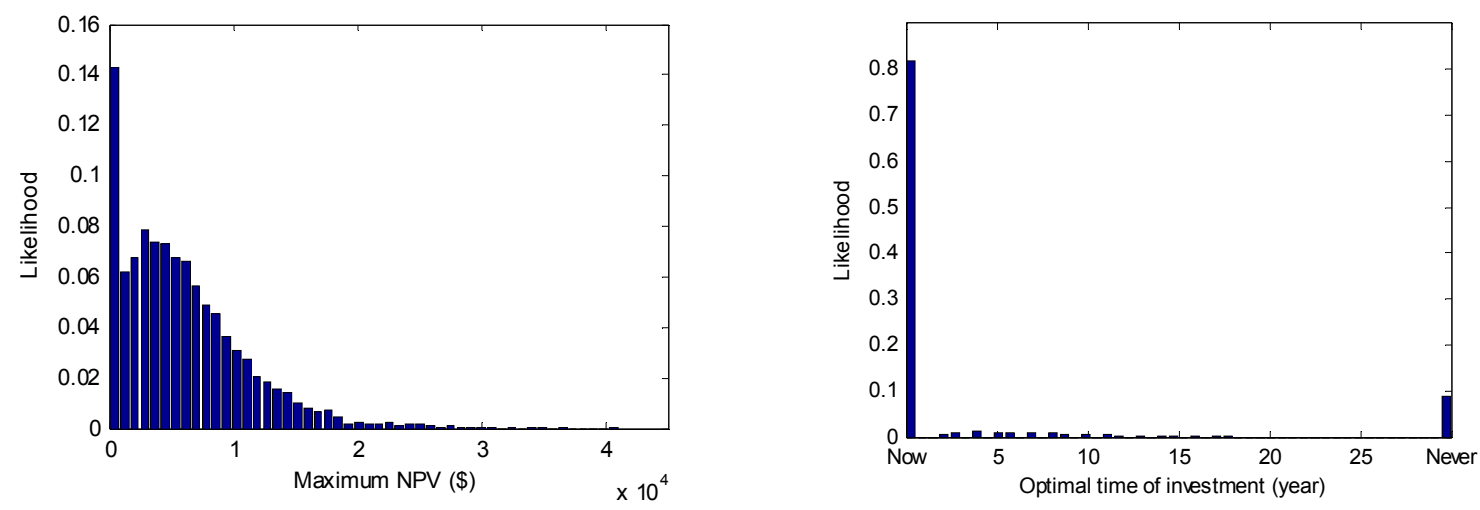

(a)
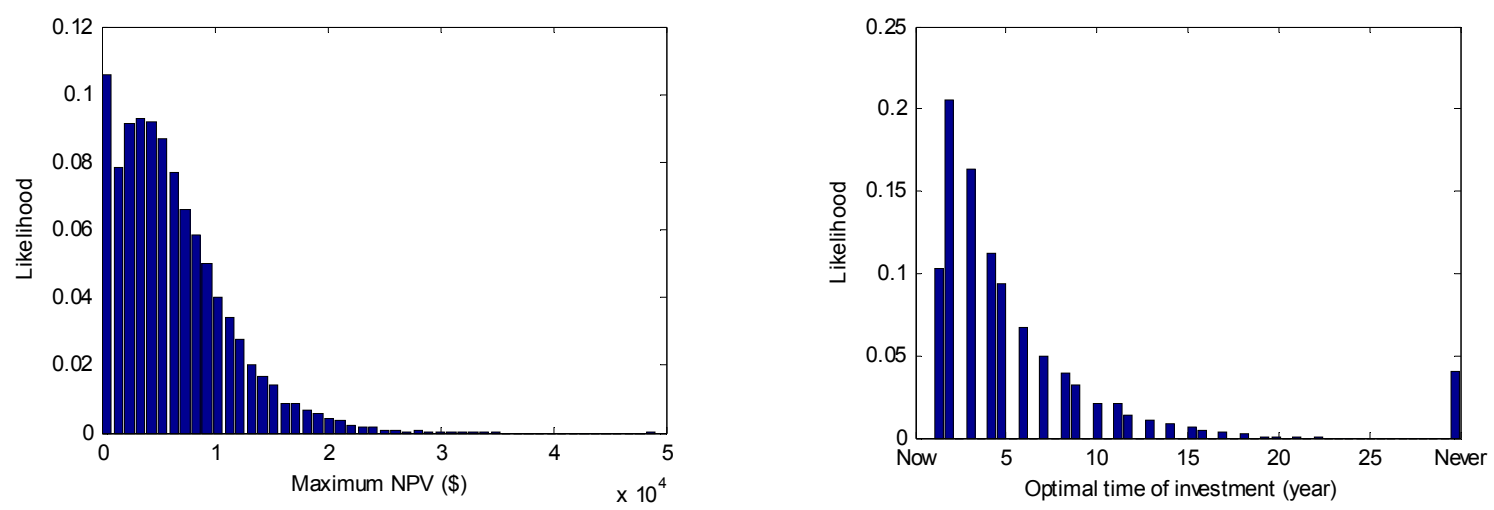

(b)
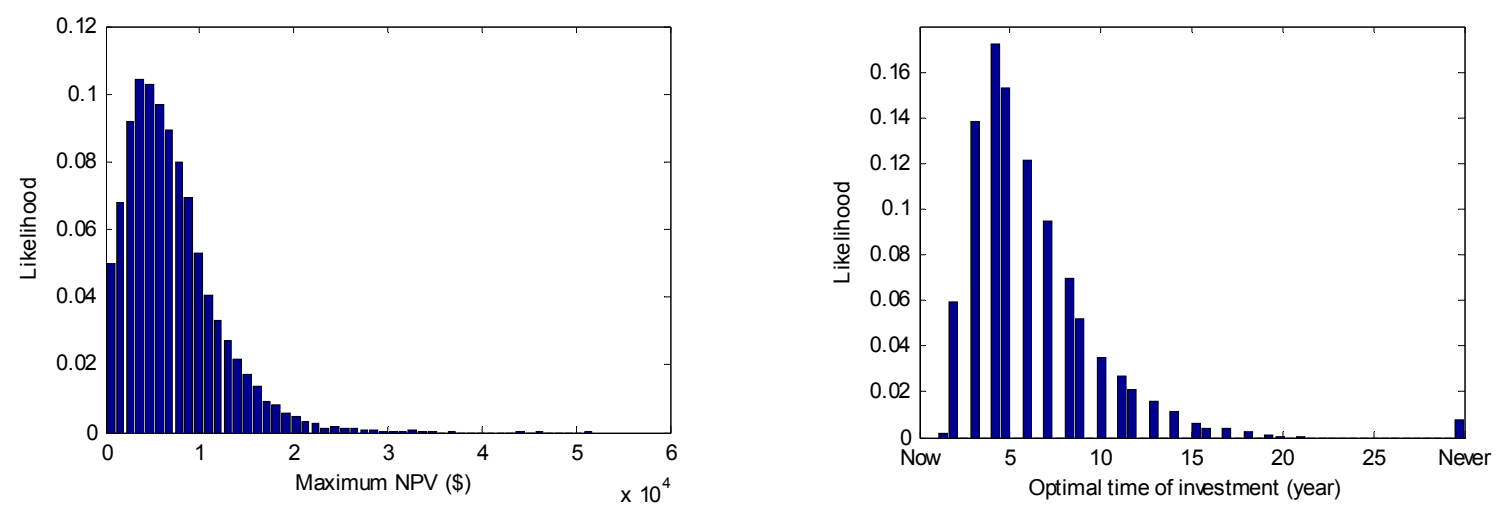

(c)

Figure 11 Maximum NPV distribution and optimal time of investment on solar panel of size $24 \mathrm{~m}^{2}$ with (a) $\gamma=0.02$ (b) $\gamma=0.04$ (c) $\gamma=0.06$. Obtained from 10000 electricity price path increases. Moreover, not surprisingly, Figure 12(a) shows that the expected NPV is not sensitive to $\gamma$ 528 for small PV size (less than $15 \mathrm{~m}^{2}$ ). This insensitivity is because of the low initial cost of small size 
solar panels. This figure also shows that for small values of $\gamma$, it is optimal to use a mid-size solar system rather than a large one. That is when the cost of solar panel drops with a small rate, the extra electricity generated by the larger solar system cannot compensate for its cost.

Figure 12(b) shows that as the size of the system increases, the expected optimal investment time is delayed to a later date. This is because as the installation cost decreases, with a larger system, more benefit (i.e., installation cost saving) can be achieved from delaying the investment. Moreover, when $\gamma$ is smaller than 0.02 , the investor is always recommended to install the system immediately no matter what system size they choose. These results are found for $\alpha=0.02$. We further explore the relationship between optimal investment time and project value with changes in the value of $\alpha$ and the size of the solar system. The value of $\gamma$ is kept at 0.04 .

Figure 13(a) shows the changes of the optimal project value with respect to solar system size and $\alpha$. It shows that when $\alpha$ is less than 0.01 , increasing the system size does not necessarily improve the project value. However, as $\alpha$ increases, the larger system size brings more value to the project. This is because higher value of $\alpha$ means higher monetary value for energy saving.

Figure 13(b) shows that at any given level of growth rate, $\alpha$, the homeowner should wait longer if they plan to invest on a larger solar system. This is because the decline in the price of technology saves the investor more money for the larger-size solar system and compensates for the time window that the homeowner continues buying electricity from the grid. Moreover, this analysis suggests that for any given size of solar system, when investors anticipate a sharp increase in the price of electricity, they should invest earlier than when their anticipation leans toward a low electricity price increase. However, for small size solar systems $\left(<10 \mathrm{~m}^{2}\right)$ the optimal investment time is independent from the electricity price growth rate, and that the homeowners should install the system regardless 
551 of the changes in price of electricity. This is due to a combination of the two factors: (a) because of

552 the small size of the systems, the owner still needs to purchase most of the energy from the grid; and

553 (b) the changes in installation cost over time do not provide high savings to the homeowner.

554 Moreover, when the growth rate of electricity price, $\alpha$ increases, the optimal investment time 555 increases for larger size systems. This is because the profit of on-site generation is increased, and 556 early installation can help investor earn more from on-site generations.

557 Figure 14 illustrates the combined effect of electricity price growth and the decline in the solar panel 558 installation cost. As it is illustrated in Figure 14 (a), when the market is predicted to change rapidly 559 (i.e. the cost of solar panels decline in near future), a higher investment value is obtained for a fixed 560 growth rate of electricity price. However, this benefit is not as significant as the effects of the 561 changes in growth rate of electricity price for a fixed value of $\gamma$. The main effect of the changes in 562 decline rate of electricity cost is on the investment timing as it is illustrated in Figure 14 (b). When 563 the rate of decline of solar panel cost is small, independent of the growth rate of electricity, it is 564 optimal to invest immediately. As the cost decline rate grows, waiting become beneficial in 565 particular when the growth rate of electricity is low. 


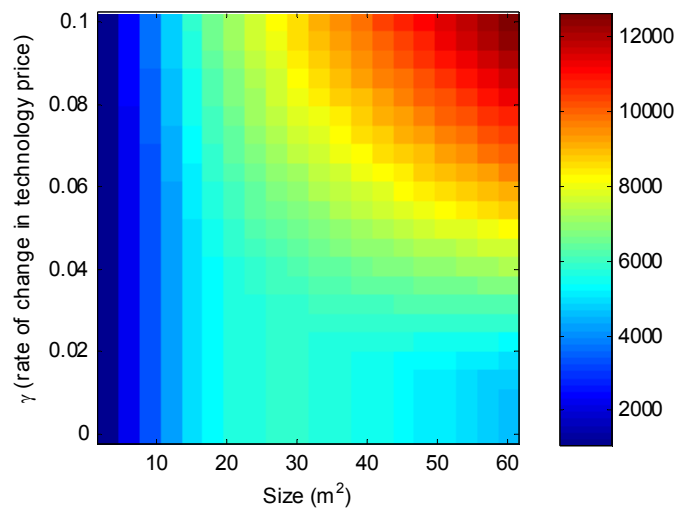

(a)

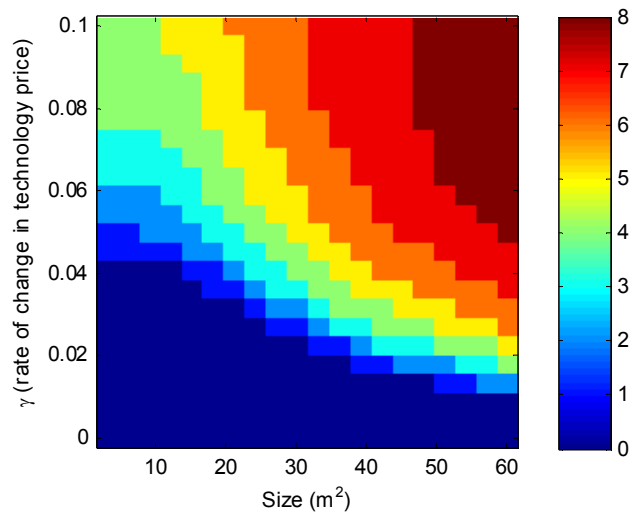

(b)

Figure 12 : Trends of (a) optimum expected project value and (b) expected time of investment with respect to solar panels size and $\gamma$

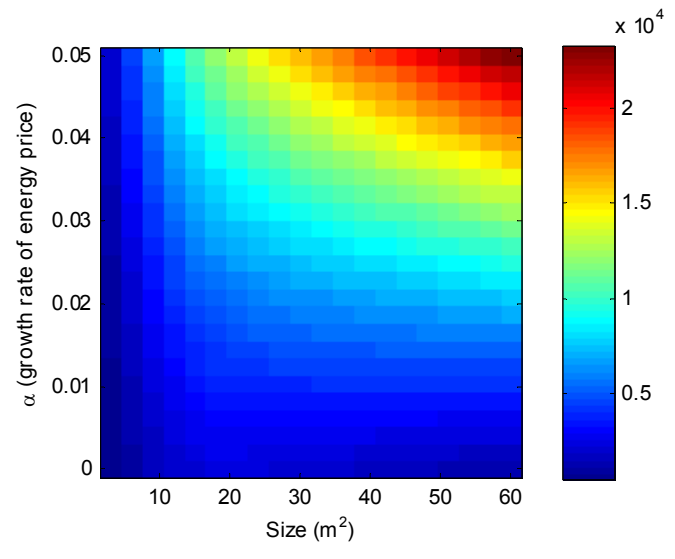

(a)

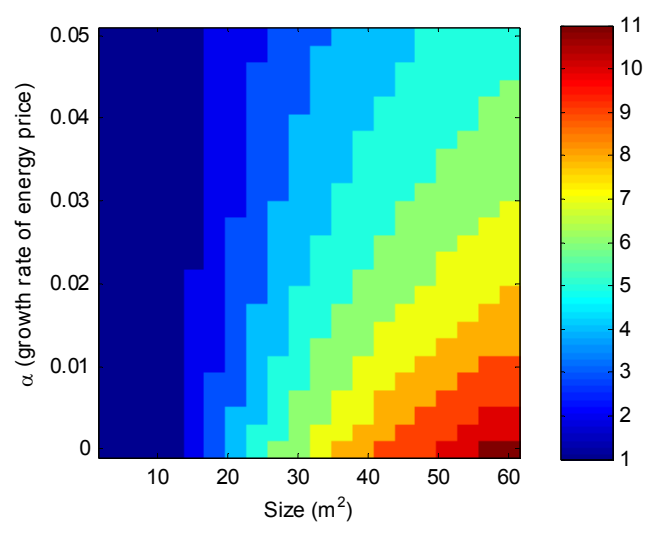

(b)

Figure 13 Trends of (a) optimum expected project value and (b) expected time of investment with respect to solar panels size and $\alpha$ (faster adoption; quicker installation; less delay) 


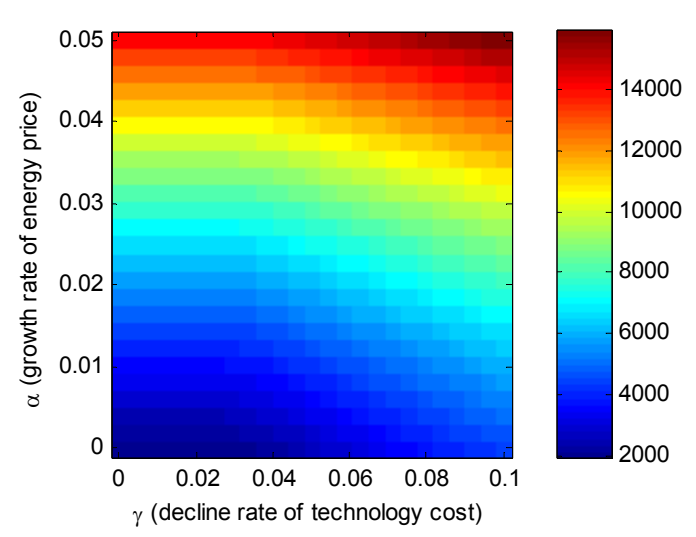

(a)

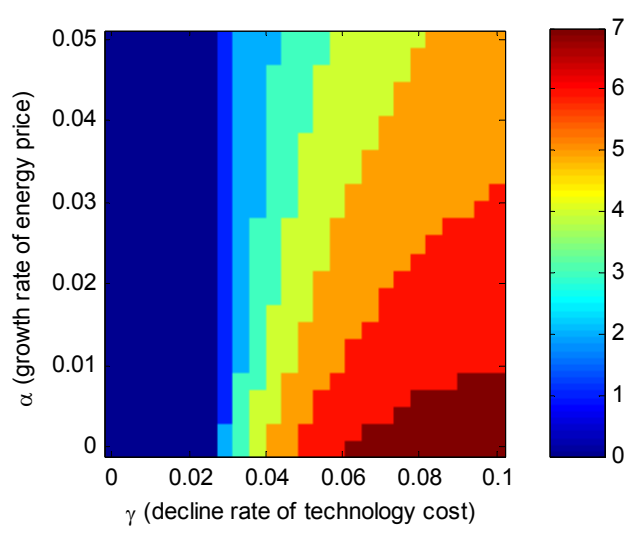

(b)

Figure 14 Trends of (a) optimum expected project value (b) expected time of investment with respect to $\gamma$ and $\alpha$.

\subsection{Investment Scenario 3: Staged investment}

This scenario explores whether staged installation of PV system can bring the homeowner more financial benefit compared to the one-time investment. The analysis is conducted using the scheme introduced in Figure 1 and discussed in section 3.4.3, to search for the optimal investment trajectory for decomposing the one time installation into different stages.

In this scenario, we assume that in any year, homeowners has two choices: (a) expand the size of their existing solar panels by $u \mathrm{~m}^{2}$, $\left(u\right.$ is a multiplier of $\left.3 \mathrm{~m}^{2}\right)$, or (b) do nothing (i.e., keep the same solar size). When increasing the size is selected the installation cost is paid for expansion, in order to start capitalizing on additional energy saving from that year. Using $C_{u}=u C(t)$ as cost of expansion, and calculating the energy saving value for each decision point by (Error! Reference source not found.), we employed the dynamic programming technique to find the optimal decision trajectory and its value. In this scenario we set $C(0)=\$ 520 / \mathrm{m}^{2}, \alpha=0.02$, and $\sigma=0.1$ to calculate the yearly cost and energy saving values. The cost of technology in each year is computed using the experience curve. 
582 Figure 15 shows the result of the staged investment strategy provided by SIDAP. From the result, we

584 investment time and size of the system instead of optimizing only one factor.

585

586

587

588

589

590

591

592

593

594

595

596

597

598

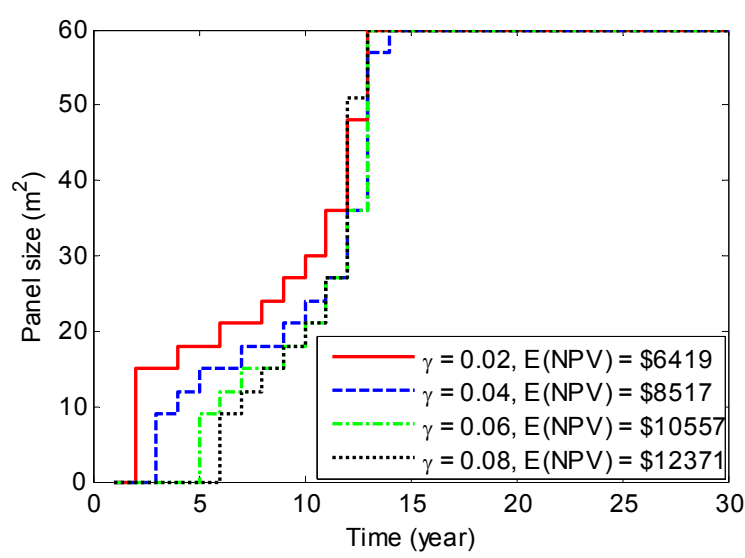

Figure 15 The optimal decision trajectory for staged investment of solar panels

In particular, by incrementing the investment the homeowner can achieve additional benefits of $\$ 1,048, \$ 782, \$ 567$, and $\$ 448$ when $\gamma=0.02, \gamma=0.04, \gamma=0.06$, and $\gamma=0.08$, respectively, compared to those investment values of the single-phase investment strategy. It is noticeable that the additional energy saving benefit takes its highest value in phased investment when it is anticipated that the technology price stabilizes $(\gamma=0.02)$. The main reason for this additional benefit is that the homeowner can gain a partial benefit from early installation of a solar system (and saving in energy cost), and obtain additional benefit later in future from reduced installation cost.

\subsection{Investment Scenario 4: The impact of climate zone to the optimal investment time}

This scenario investigates what effect the location of the house has on the delaying options. To answer this question, we choose four different locations in the U.S.: Phoenix, Atlantic City, Atlanta and Chicago. Phoenix is in climate zone 2B, where the weather is hot and dry. It is among the cities that receive the highest amount of yearly sunshine in the U.S. Atlantic City is in climate zone 4A, 
599

600

601

602

604

605

606

607 608

609

610

611

612

where the weather is humid and cloudy. Atlanta is in climate zone $3 \mathrm{~A}$, where the weather is warm and humid. Chicago is in climate zone 5A, where the weather is cool and humid.

Figure 16 shows how the expected NPV (in a now or never investment case) of the solar investment changes as a function of the size of the residential PV system in different locations (sellback ratio is 0.5). As it is illustrated, the expected NPV of solar investment in Phoenix is always positive, and is optimal for the sizes in range 30 to 40 square meters. However, for other cities with lower amount of yearly sunshine, the expected NPV of solar energy investment becomes negative if large solar panels are installed. Furthermore, for these cities (Atlantic City, Atlanta, and Chicago), the optimal size of solar panels is about the half of the optimal size of the panels in Phoenix, and their expected NPV is about a third of the Phoenix's.

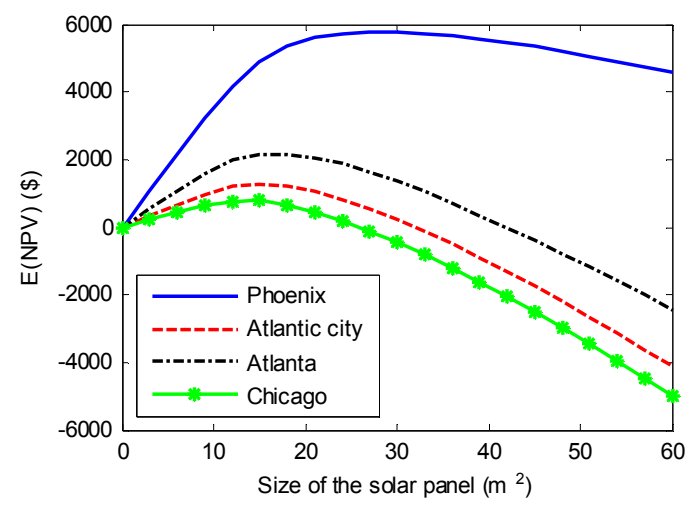

Figure 16 Expected value of the PV system at different system sizes for four U.S. cities (sellback ratio = 0.5)

The optimal solar panel sizes calculated in Figure 16 were used to compare the investment paybacks and timing at each of the locations in the case with option to delay the investment. 


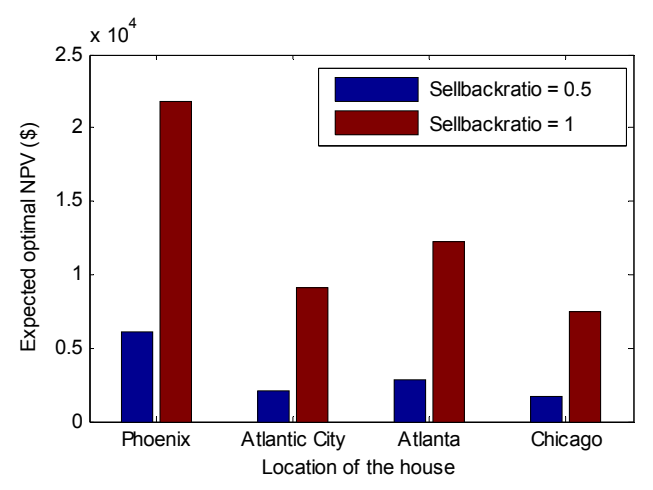

(a)

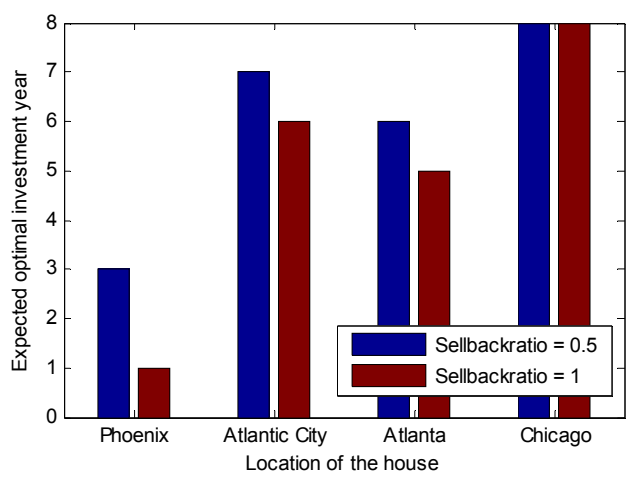

(b)

Figure 17 (a) The optimal $E(N P V)$ (b) the expected optimal investment time for different locations

Figure 17(a) shows the expected NPV for each of the locations for two electricity payback ratios, when $\alpha=0.02, \sigma=0.1$, and $\gamma=0.04$. Not surprisingly, Phoenix has the highest $E(N P V)$ for both sellback ratios. The house in Atlanta, Atlantic City, and Chicago follows the house in Phoenix in terms of expected NPV.

Figure 17(b) indicates that the optimal time of investment for a same house changes depending on the overall weather condition. The homeowner is recommended to wait longer as the house location has less sun radiation over a year. In Phoenix, the earlier installation means more profit from using the produced PV energy instead of purchasing electricity from the grid. For a house in Chicago that has the least expected NPV from solar investment, it is recommended to wait for 8 years to install the system. In this city, the financial benefit that comes from the decreased installation cost is more than the benefit of using PV to reduce electricity purchased from the grid.

Finally Figure 17 (a) and 17(b) show the impact of the sellback ratio on the optimal NPV and timing of investment. For phoenix, since the amount of electricity generated by the solar system can exceed the homeowner demand, the higher sell back ratio generates a great benefit, and removes the need for waiting. However, in Chicago, the solar panel production cannot exceed the demand and hence, 
changing the sell back ratio does not change the optimal investment time.

\section{CONCLUSIONS AND FUTURE WORKS}

This paper inspects the coupled role of investment timing and system sizing in the decision-making about residential PV systems. EnergyPlus software, Geometric Brownian Motion (GBM), and experiment curve have been used to simulate building uncertainties, model the monthly average price of electricity, and predict the solar panel installation cost respectively. Moreover, the dynamic programming approach has been employed to identify the optimal sizing of the solar panels in a multi-phase investment. Finally, four different design scenarios were built to evaluate the interactive effects of changes in electricity price, demand, installation cost, and sizing of the panels on the investment in solar system. In particular, each design scenario explores the impact of certain decision making parameters on the overall profit that the PV system can achieve over its lifespan. Based on the results, the following is concluded:

- It is not always optimal to install the largest size of the solar panels when the sellback ratio is smaller than one. This decision highly depends on the growth rate of the electricity price, and the sellback ratio.

- The demand side uncertainty impacts the variation of $E(N P V)$ only when the sellback price of electricity is lower than the retail price of electricity.

- In general, delaying the investment might be an effective strategy to increase the profit of investing on solar system. However, the duration of this delay depends extensively on the rate of changes in the electricity price and the installation cost of solar panels. When the market is stable for both the electricity price and the solar panel, depending on the situation, one should either invest immediately or never invest. When the investor predicts that significant changes 
651

652

653

654

655

656

657

658

659

660

661

662

663

664

665

666

667

668

669

670

671

672

will appear in any of the markets, it is more reasonable for the investor to wait (refer to Figure 11, 12, 13, and 14).

- Phasing the investment can leverage benefits from both saving the energy, and reduction in solar panels costs. As a result, investing in solar systems in several phases, rather than one single phase, increase the total return of the project. In particular, when the solar market is stable phasing the investment can gain the highest value. In the presented case study, this value was up to $\$ 1048$ from the total net present value of $\$ 6419$ (Figure 15).

- Location plays an important role in investment decisions. In different climate zones, the optimal investment time and expected optimal NPV varies for identical houses. Moreover, climate zone can reduce the effect of sellback ratio on the timing of the investment. For example, the sellback ratio has no influence of the investment timing in Chicago. This is because, in the areas with lower solar radiation, the total electricity generated by the solar system is most likely less than the demand, and therefore the owner will not sell to the grid.

The result of this study suggests that the investor would not completely capture the whole value of investment in the PV system unless the investor thoroughly took into account the significant coupled role of timing and system sizing in each decision scenario.

The use of GBM processes in real options analysis has not been without difficulties. Some underlying modeling assumptions may not hold in practice. For instance, the assumption of constant volatility rate over time may not be good in some problems. Also, GBM process is not a good modeling choice in capturing sudden substantial changes (jumps) of the underlying uncertain variable. Other stochastic processes, such as mean reverting and jump processes [44, 45], should be further studied to examine their applicability in modeling uncertain electricity prices. 
673

674

675

676

677

691

There are several potential issues that should be addressed to fully utilize the possible advantages of these complex stochastic models. For instance, several parameters are required to be estimated before applying mean reverting process: mean reversion rate, volatility, jump size, and jump frequency with seasonality. Often a substantially large dataset does not exist to properly estimate all the parameters. This is a critical barrier in implementing other sophisticated stochastic processes in real option analysis for renewable energy systems [44].

Other factors, such as advances in high-capacity batteries technologies, are critical in decision-making about investment in solar energy. Studying the effects of future innovation in battery technologies is beyond the scope of this study. In future works, we plan to investigate the efficiency and capacity of emerging battery technologies and examine the effects of developments in the battery market on investment decisions in integrated PV-battery systems. There are several interesting research questions that should be studied further. For instance, given the sellback ratio and other decision parameters, what is the optimal strategy in producing, consuming, storing, and selling the renewable electricity generated by the PV system? The proposed SIDAP investment decision-making framework provides a solid foundation for expanding the scope of the study to include the emerging opportunity to utilize battery systems as an integrated part of building energy systems.

\section{NOMENCLATURE}

\begin{tabular}{|c|c|}
\hline$p$ & Retail price of electricity that we assumed follows a GBM model \\
\hline$\alpha$ & The growth rate of electricity price over time \\
\hline$\sigma$ & Volatility of electricity price \\
\hline$r$ & Discount rate or market interest rate \\
\hline$C_{t}$ & Solar panel installation cost at time $t$ \\
\hline$X_{t}$ & Commutative solar production \\
\hline$\beta$ & $\begin{array}{l}2^{-\beta} \text { is the progress ratio (PR), which can be considered to be between } 0.7 \\
\text { and } 0.85\end{array}$ \\
\hline
\end{tabular}




\begin{tabular}{|c|l|}
\hline$\gamma$ & The growth rate of solar panel cost \\
\hline$z$ & $\begin{array}{l}\text { The amount of electricity that solar panel generates in } k W h, \text { on average } \\
\text { during a year }\end{array}$ \\
\hline$D$ & $\begin{array}{l}\text { Amount of electricity the household consumes in kWh on average during a } \\
\text { year }\end{array}$ \\
\hline$m$ & Average yearly maintenance cost \\
\hline$\varepsilon$ & Electricity sellback ratio \\
\hline$V(t, p)$ & Expected energy saving value if the investment appears at time $\mathrm{t}$ \\
\hline$F(t, p)$ & $\begin{array}{l}\text { optimal expected value of the project at time } t \text { when the retail price of } \\
\text { electricity is } p(t)\end{array}$ \\
\hline$V_{u}^{t}$ & Value of energy saving for panel size $u$ during the year $t$. \\
\hline$C_{u_{i}, u_{j}}^{t}$ & $\begin{array}{l}\text { Cost of changing panel size from } u_{i} \text { to } u_{j} \text { at time t. That is the panel of } \\
\text { size } u_{j} \text { obtained at time t. }\end{array}$ \\
\hline$W_{u}^{t}$ & The optimal total value to reach size $\mathrm{u}$ at time $\mathrm{t}$ from time 0. \\
\hline$T$ & Project lifetime \\
\hline$t, \tau$ & $\begin{array}{l}\text { Represents time. In equation }(3) \text { represents time of investment and } \\
\tau \text { represents time. }\end{array}$ \\
\hline
\end{tabular}




\title{
7. AKNOWLEDGEMENT
}

\author{
This material is based upon work supported by the National Science Foundation under Grants
}

No. 1300918,1441208 , and 1038248.

\section{REFRENCE}

1. DOE. Buildings energy data book. 2010; Available from: http://buildingsdatabook.eere.energy.gov/.

2. Energy Information Administration (EIA), Annual energy review. 2011.

3. Yudelson, J., Greening existing buildings, in McGraw-Hill's GreenSource series. 2010, McGraw-Hill,: New York. p. 1 online resource (308 pages).

4. Solar Energy Industries Association. Solar market insight report 2014 Q1. 2014 [cited 2015 January]; Available from: http://www.seia.org/research-resources/solar-market-insight-report-2014-q1.

5. Ashuri, B. and H. Kashani. A real options approach to evaluating investment in solar ready buildings in Computing in Civil Engineering. 2011.

6. Lee, H.W., K. Choi, and J.A. Gambatese, Real option valuation of phased investment in commercial energy retrofits under building performance risks. Journal of Construction Engineering and Management, 2014. 140(6).

7. Menassa, C.C., Evaluating sustainable retrofits in existing buildings under uncertainty. Energy and Buildings, 2011. 43(12): p. 3576-3583.

8. Kumbaroglu, G. and R. Madlener, Evaluation of economically optimal retrofit investment options for energy saving in buildings. Energy and Buildings, 2012. 49: p. 327-334.

9. Pyper, J. Solar Is Cheaper Than the Grid in 42 of the 50 Largest US Cities. 2014 [cited 20.01.2015; Available from: http://www.greentechmedia.com/articles/read/report-solar-is-cheaper-than-the-grid-in-42-of-the-50-largest-us-cities?u $\underline{\mathrm{tm} \text { source}=\text { Daily\&utm medium=Headline\&utm campaign }=\text { GTMDaily. }}$.

10. Kashani, H., et al., Investment valuation model for renewable energy systems in buildings. Journal of Construction Engineering and Management, 2015. 141(2).

11. Martinez-Cesena, E.A., B. Azzopardi, and J. Mutale, Assessment of domestic photovoltaic systems based on real option theory. Progress in Photovoltaics, 2013. 21: p. 250-262.

12. Van der Maaten, E., Uncertainty, Real Option Valuation, and policies toward a sustainable built environment. The Journal of Sustainable Real Estate (JOSRE), 2010. 20(1): p. 161-180.

13. Dixit, A.K. and R.S. Pindyck, Investment under uncertainty. 1994, Princeton, N.J.: Princeton University Press. xiv, $468 \mathrm{p}$.

14. Ford, D.N. and M. Garvin, Barriers to real options adoption and use in AEC project management practice, in Real options in engineering design, operations, and management, H.B. Nembhard, Editor. 2010, CRC Press: London, U.K.

15. Borison, A., Real options analysis: Where are the emperor's clothes? Journal of applied corporate finance, 2005. 17(2): p. 7-31.

16. Ellingham, I. and W. Fawcett, New Generation Whole-Life Costing: property and construction decision-making under uncertainty. 2006, London: Taylor and Francis.

17. Kim, B., et al., Determining the value of governmental subsidies for the installation of clean energy systems using real options. Journal of Construction Engineering and Management, 2012. 138(3): p. 422-430.

18. Crawley, D.B., et al., EnergyPlus: creating a new-generation building energy simulation program. Energy and 
Buildings, 2001. 33(4): p. 319-331.

19. De Wit and Augenbroe, Analysis of uncertainty in building design evaluations and its implications. Energy and Buildings, 2002. 34(9): p. 951-958.

20. Lee, B.D., et al. Towards better prediction of building performance: A workbench to analyze uncertainty in building simulation. in 13th International Conference of the International Building Performance Simulation Association. 2013.

21. Macdonald, I.A., Quantifying the effects of uncertainty in building simulation. 2002, University of Strathclyde.

22. Saltelli, A., et al., Global sensitivity analysis: the primer. 2008: John Wiley \& Sons.

23. Sun, Y., et al., Uncertainty quantification of microclimate variables in building energy models. Journal of Building Performance Simulation, 2014. 7(1): p. 17-32.

24. Lee, B.D., et al. A framework for generating stochastic meteorological years for risk-conscious design of buildings. in Proceedings of 5th National Conference of IBPSA-USA, SimBuild. 2012.

25. Sun, Y., et al. Uncertainty Quantification of Solar Diffuse Irradiation on Inclined Surfaces for Building Energy Simulation. in Proceedings of Building Simulation. 2013.

26. Perez, R., et al. , Modeling daylight availability and irradiance components from direct and global irradiance. Solar energy 1990. 44(5): p. 271-289.

27. Wang, Q., G. Augenbroe, and Y. Sun. The role of construction detailing and workmanship in achieving energy efficient buildings. in Construction Research Congress. 2014.

28. Hu, H., risk-conscious design of off-grid solar energy houses, in College of Architecture. 2009, Georgia Institute of Technology

29. Khazaii, J., Effects of sub-optimal component performance on overall cooling system energy consumption \& efficiency. 2012, Georgia Institute of Technology.

30. Augenbroe, G., et al. Implications of the uncoupling of building and HVAC simulation in the presence of parameter uncertainties. in Proceedings of Building Simulation. 2013.

31. Sun, Y., Closing the building energy performance gap by improving our predictions. 2014, Georgia Institute of Technology.

32. Cui, Q., et al., Valuing the warranty ceiling clause on New Mexico highway 44 using a binomial lattice model. Journal of Construction Engineering and Management, 2008. 134(1): p. 10-17.

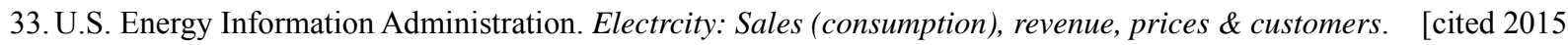
8/10/2015]; Available from: http://www.eia.gov/electricity/data.cfm\#sales.

34. Marathe, R.R. and S.M. Ryan, On the validity of the geometric Brownian motion assumption. The Engineering Economist, 2005. 50(2): p. 159-192.

35. Bradley, J.V., Distribution-free statistical tests. 1968.

36. Wirth, H., Recent facts about photovoltaics in Germany. 2015, Fraunhofer.

37. Feldman, D., et al., Photovoltaic system pricing trends. 2014, SunShot U.S. Department of Energy.

38. Nemet, G.F., Beyond the learning curve: factors influencing cost reductions in photovoltaics. Energy Policy, 2006. 34(17): p. 3218-3232.

39. Albrecht, J., The future role of photovoltaics: A learning curve versus portfolio perspective. Energy Policy, 2007. 35(4): p. 2296-2304.

40.Burger, B., et al., Photovoltaics report. 2014, Fraunhofer Institute for Solar Energy Systems ISE: Freiburg (Germany). p. 1-42.

41. SMUD. SMUD feed-in tariff. 2015 [cited 2015 September]; Available from: https://www.smud.org/assets/documents/pdf/FIT-Pricing.pdf.

42. SMUD. SMUD rate changes for 2014 - 2017. 2015 [cited 2015 September]; Available from: https://www.smud.org/en/residential/customer-service/rate-information/rates-2014-2017.htm. 
777 43. Zhang, Y. and G. Augenbroe. Right-sizing a residential photovoltaic system under the influence of demand response $778 \quad$ programs and in the presence of system uncertainties. in Building Simulation. 2014.

779 44. Skantze, P., M. Ilic, and J. Chapman, Stochastic modeling of electric power prices in a multi-market environment, in $780 \quad$ Power Engineering Society Winter Meeting. 2000, IEEE. p. 1109-1114.

781 45. de Lange, A.J.P., P.H. Schavemaker, and L. van der Sluis, Electricity prices: Stochastic or deterministic? 2002, ADL

782 Consultancy: Netherlands.

783 